\title{
Arranhando o céu: os edifícios altos como manifestação de cultura
}

MÔNICA AgUiAR - Engenheira, Professora de Estruturas e Pesquisadora

Escritório Justino Vieira Monica Aguiar Projetos Estruturais — PUC-Rio

\author{
MARCOS FaVero - Professor de Projeto e Pesquisador \\ Curso de Arquitetura e Urbanismo — Programa de Pós-Graduação da PUC-Rio
}

\section{RESUMO}

Marco de uma lóGICA dE EXPANSÃo ESPACIAL VERTICALIZADA, POSSIBILITADO PELO DESENVOLVIMENTO DE TÉCNICAS DE PROJETO E CONSTRUÇÃO DE ESTRUTURAS, OS EDIFÍCIOS ALTOS SURGIRAM INICIALMENTE em Chicago e Nova York, nos Estados Unidos, e se espalhaRAM PELO MUNDO OCIDENTAL COMO EXPRESSÃO DO PODER DO SETOR

IndUStRIAL. ATUalmente, esses edifícIOS PODEM ATINGIR ALTURAS QUE PASSAM DOS 600 METROS E FIGURAM COMO EXPRESSÃO DE UMA CULTURA PLANETÁRIA CUNHADA PELAS GRANDES CORPORAÇÕES TRANSNACIONAIS, EXPRESSANDO VALORES INTRÍNSECOS DO CAPITALISMO TARDIO NO MUNDO GLOBALIZADO.

Palavras-chave: edifícios altos, cultura, capitalismo, engenharia, arquitetura.

\section{INTRODUÇÃO}

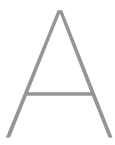

proposta desse artigo é examinar os edifícios altos como manifestação cultural, não apenas atrelada ao desenvolvimento da técnica, mas também como materialização das aspirações de uma sociedade. Por meio do patrimônio construído é possível observar aspectos relacionados às sociedades no que diz respeito ao conhecimento adquirido ao longo do tempo, às manifestações artísticas, aos costumes e crenças, bem como às leis e estatutos morais, todos estes campos da cultura.

No caso dos edifícios altos, trata-se de manifestação cultural cuja origem está diretamente relacionada ao processo de consolidação da Revolução Industrial, a partir de meados do século XIX. Fenômeno que fez surgir dois novos materiais de construção: o aço e o concreto armado.
Materiais que revolucionaram o saber construtivo desenvolvido ao longo de séculos - fundamentado em paredes portantes - possibilitando sistemas estruturais independentes de elementos de vedação, que serviriam à arquitetura e à engenharia para atender às demandas de uma sociedade em acelerado processo de modernização.

Os desdobramentos da Revolução Industrial afetaram diferentemente os países europeus e os Estados Unidos da América (EUA). No caso da Europa, a industrialização atingiu uma cultura milenar, materializada em um patrimônio construído que, já no século XIX, era objeto de estudos ligados à sua conservação como patrimônio histórico. Nos EUA, ao contrário, por força de seu passado colonial, tudo estava por fazer e ali, em um contexto histórico e geográfico particular, uniram-se capacidade econômica e criativa, permitindo o desenvolvimento de um tipo de edificação sem precedentes históricos: o edifício alto. Edificação que passou a ser símbolo de uma sociedade capitalista, próspera e industrializada, em vertiginosa modernização.

Fazendo um percurso que tem início na década de 1880 em Chicago, procura-se compreender como os edifícios configuraram-se como símbolo material da cultura industrializada eurbana dos EUA. Cultura que acabou por se difundir mundialmente, sobretudo a partir de meados século $X X$, tendo sido apropriada como cultura planetária no início do século XXI.

\section{A ESCOLA DE CHICAGO}

A origem da construção de edifícios altos pode ser atribuída às demandas provenientes da modernização acelerada resultante da Revolução 
Industrial, que acabaram por ser resolvidas, primeiramente, pelo campo da engenharia. Essas demandas materializaram-se em grandes pavilhões de exposições, estações ferroviárias, mercados, lojas de departamentos e símbolos culturais, cujo exemplo mais significativo foi a torre projetada e construída pelo engenheiro Gustave Eiffel (1832-1923), para a Exposição Universal de 1889. Torre que pode ser considerada um ícone relacionado às técnicas de projeto e construção de estruturas metálicas - protagonistas do patrimônio construído em meio às transformações urbanas que se deram nos centros da vida européia no final do século XIX.

A Europa industrializada, que tinha em Paris o seu centro de referência cosmopolita, trazia consigo, no entanto, toda a tradição artística de uma cultura milenar. Lá se encontravam as universidades para onde acorriam jovens de várias partes do mundo em busca da melhor formação artística e técnica. Seria preciso que uma geração de jovens arquitetos e engenheiros, provenientes de famílias abastadas da aristocracia dos EUA, frequentasse as universidades europeias, principalmente na França, para que o cenário da construção em aço começasse a mudar.

Originários de uma cultura sem o peso do passado europeu e fundada sobre bases pragmáticas, os engenheiros norte-americanos revolucionaram a construção em aço. William le Baron Jenney (1832-1907) é um dos exemplos dessa mudança, que surgiu em Chicago, no estado de Illinois. Jenney formou-se na École

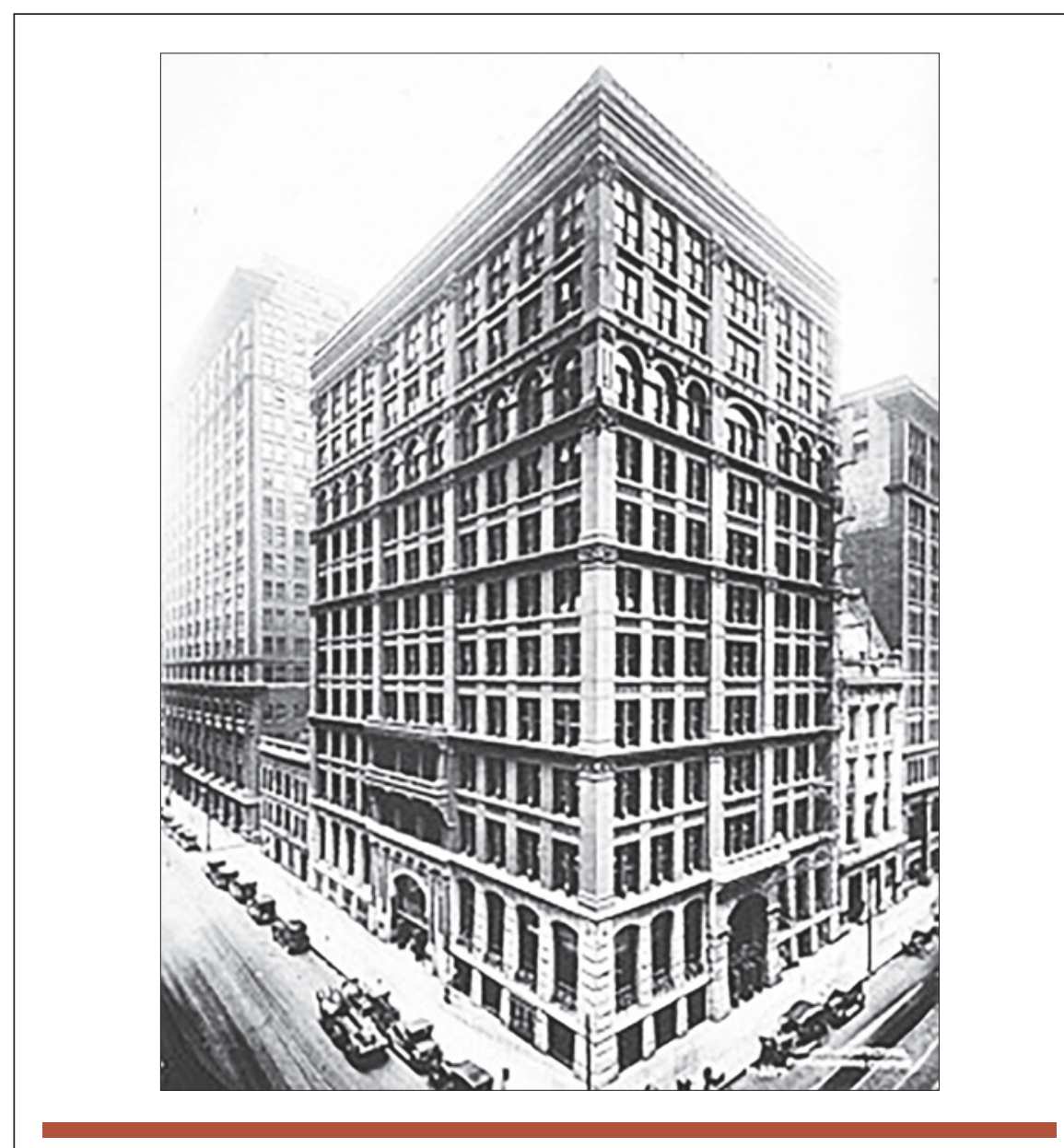

Figura 1

The Home Insurance Building, 1885. William Le Baron Jenney

Polytechnique e na École Centrale, em Paris, tendo recebido o que era então considerada a melhor formação de seu tempo. Segundo o historiador de arquitetura Siegfried Gideon, "no escritório de Jenney, a engenharia francesa combinada aos métodos de especialistas alemães produziu uma mistura curiosa"1. Uma mistura que procurava conciliar e refletir as funções de uso de uma edificação na sua arquitetura, subvertendo regras consagradas de composição arquitetônica, estabelecidas originalmente pela École des Beaux-Arts de Paris.
Em 1893 foi realizada em Chicago a Exposição Universal Colombiana e naquele momento o público estrangeiro pode tomar conhecimento da arquitetura do centro de Chicago. Após o incêndio de 1871, que destruiu praticamente toda a cidade, deu-se a reconstrução, que foi intensificada no período entre 1880 e 1900. A cidade transformou-se em um laboratório de novas experiências arquitetônicas, embasadas pela evolução das técnicas estruturais, construtivas, de comunicação e mecânicas; 
cenário no qual foi preponderante a atuação do engenheiro Jenney e do arquiteto Louis Sullivan (1856-1924).

Em 1879, Jenney construiu o primeiro edifício alto de estrutura metálica, com 138 pés de altura (42,06m), configurado por um sistema estrutural em esqueleto que liberava as alvenarias da responsabilidade de suporte da edificação. Com isso possibilitou a construção de janelas maiores, que permitiam a iluminação e a ventilação dos ambientes mais afastados do plano das fachadas. Neste contexto, o elevador, inovação técnica apresentada pelo engenheiro Elisha Graves Otis (1811-1861) em Nova York em 1857,e outras novas tecnologias, como o telefone e o correio pneumático contribuíram diretamente no projeto e construção de edifícios de grande altura, inicialmente ocupados por escritórios, hotéis e lojas de departamentos.

O arranha-céu se insere na paisagem de Chicago e, de modo similar ao planejamento urbano de matriz quadriculada presente na cidade - e, em tantas outras mundo afora, como Nova York e Buenos Aires - o edifício alto passa a refletir a lógica da expansão espacial por adições sucessivas, representando a expansão da cidade na direção do céu (Figura 1).

Cabe ressaltar que, para além do surgimento dessa nova modalidade de construção como fenômeno técnico e material, a configuração do edifício alto como fenômeno da cultura pode ser atribuída a Sullivan, que em 1896 problematizou a questão:

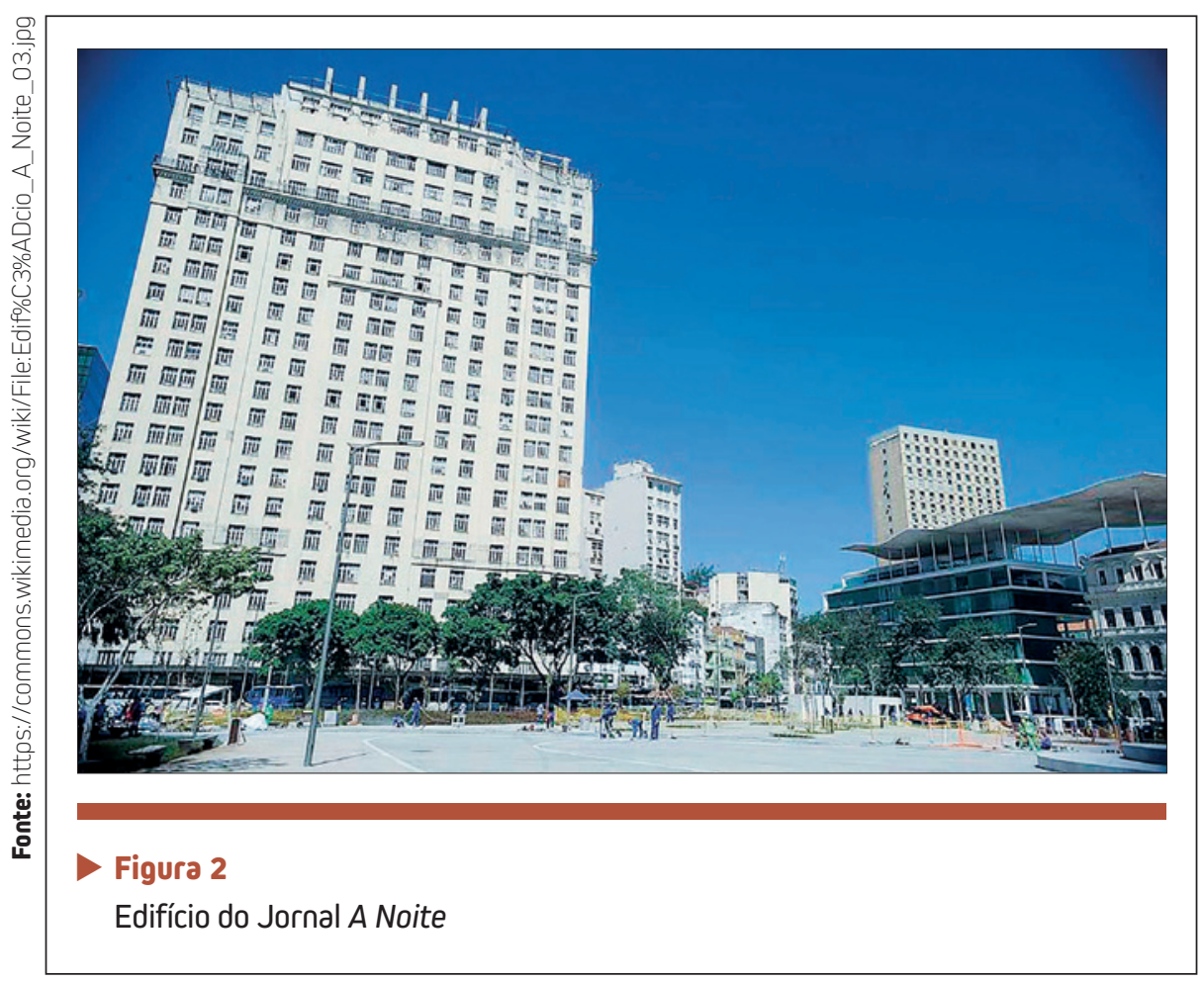

Os arquitetos dessa terra e geração agora devem encarar algo novo sob o sol, a saber, a evolução e integração de condições sociais, aquele agrupamento especial delas, resultando em uma demanda por edifícios de grande altura [...]. O problema: como conferiremos a essa pilha estéril, a essa exclamação rude e espalhafatosa da eterna luta, a graça daquelas formas mais elevadas de sensibilidade e cultura? ${ }^{2}$

Sullivan manifestou-se criticamente com relação à arquitetura dos edifícios altos que vinham sendo construídos em Chicago, considerando que não bastava à arquitetura continuar repetindo fórmulas acadêmicas na sua construção e posicionando-se "a favor de uma moratória na ornamentação"3. O edifício alto, assim como as estações ferroviárias, os grandes mercados cobertos e outros programas inovadores, trouxe para a arquitetura questões sem precedentes históricos, portanto fora do espectro de certo raciocínio compositivo, de matriz Beaux-Arts, no qual a ornamentação era questão intrínseca. Colunas neoclássicas ornamentais e apliques neogóticos, por exemplo, perdiam sentido em fachadas cuja proporção entre largura e altura não tinham qualquer relação com essas referências históricas. É neste sentido que Sullivan sugere uma moratória na ornamentação e preconiza que a forma arquitetônica deveria seguir a sua função, e, consequentemente, não mais se submeter a regras acadêmicas de composição arquitetônica. 
Após o fim da I Guerra Mundial e antes da crise financeira de 1929, a construção de edifícios altos intensificou-se nos grandes centros urbanos de cidades dos EUA. Edifícios de negócios foram construídos no centro, enquanto os bairros residenciais foram direcionados para seus arredores, a partir da implementação do automóvel como meio de transporte individual. Tanto Chicago quanto a cidade de Nova York afirmaram-se então como os grandes laboratórios onde se desenvolveu a técnica de construção e projeto do arranha-céu.

A pilha estéril, rude e espalhafatosa ganharia o mundo a partir dali e viria a se transformar em um dos símbolos da cultura norte-americana, exportada para vários países do mundo como o "american way of life".

\section{O ARRANHA-CÉU CHEGA AO BRASIL}

A verticalização da construção no Brasil está ligada à tecnologia do concreto armado. No início do século $X X$ alguns edifícios altos vinham sendo construídos em concreto armado tanto nos EUA como em alguns países da América do Sul. Augusto Carlos de Vasconcelos menciona dois edifícios que marcaram o início do processo de verticalização das construções no Brasil: o edifício A Noite, no Rio de Janeiro, e o Edifício Martinelli,em São Paulo, ambos construídos entre 1927-1929.

$\mathrm{O}$ edifício A Noite, projeto do ar-

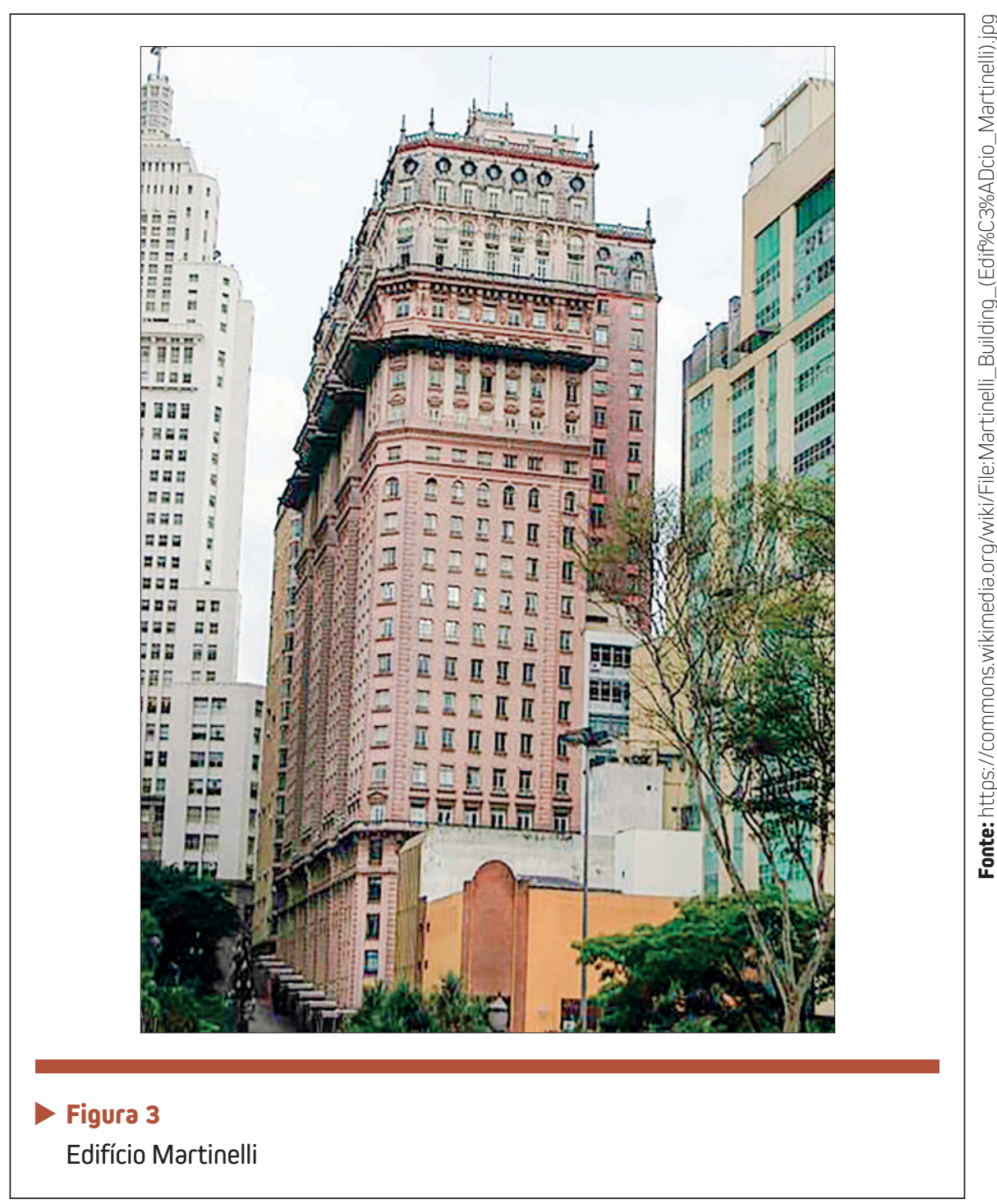

quiteto francês Joseph Gire (1872Martinelli de construir o edifício mais 1933) e do arquiteto brasileiro Elisário Bahiana (1891-1980), teve seu projeto estrutural elaborado pelo engenheiro Emílio Baumgart (1889-1943). O edifício, após o acréscimo de dois pavimentos previstos no projeto original, porém construídos em 1930, atingiu a altura de $102,80 m$. Por sua vez, consta que o Edifício Martinelli nasceu da vontade do Comendador Giuseppi alto da América do Sul. Após sucessivas modificações de projeto, que segundo Vasconcelos podem ter surgido de certo espírito competitivo entre as duas cidades, o edifício acabou sendo finalizado com 105,65m de altura, pela construção de uma "casa" a partir do $26^{\circ}$ pavimento ${ }^{4}$ (Figuras 2 e 3).

No Brasil, foi o arquiteto Lucio Costa (1902-1998) que, em 1928,

\footnotetext{
VASCONCELOS, 1992, P.44-45.

Além dos eXemplos brasileiros, o autor menciona alguns edifícios construídos nos EUA: o Ed Ingalls, em Cincinatti, 1903, 64M de altura; o Hotel Trymore, em AtLantic City, New Jersey que quebrou o recorde estabelecido pelo Ingalls; o Medical Arts Building em Dallas, 1922, 70m de altura; além do edifício Salvo, em Montevidéu, construído EM 1926 COM 45,60 M DE ALTURA SOBRE O QUAL FOI ACRESCIDA UMA TORRE QUE ATINGE 102,50 M.
} 


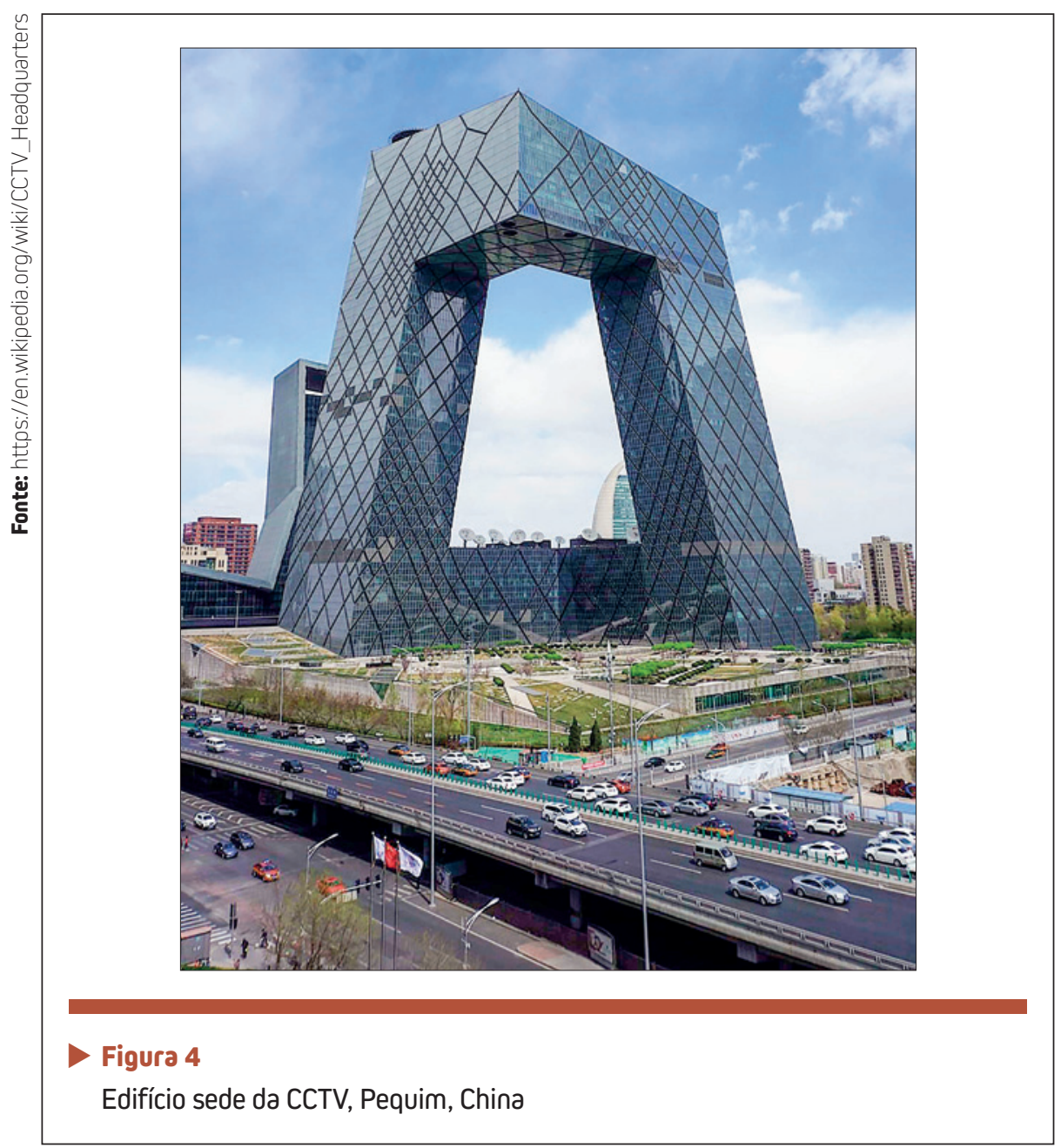

pronunciou-se a respeito do arranha-céu como fenômeno de cultura. Respondendo a uma série de perguntas formuladas pelo jornal O País, na edição de $1^{\circ}$ de julho de 1928, Costa reflete sobre o significado do projeto e construção desse tipo de edificação, associando sua materialização a um objeto de "exaltação coletiva", um símbolo do progresso, construído a partir de uma forma moderna. Forma autônoma, oriunda de elementos da geometria pura, fundamentada no princípio "forma segue função", pressuposto intrínseco ao ideário da Arquitetura Moderna. Critérios de beleza, proporção, composição e ornamentação de índole acadêmica deixariam de ser mandatórios, abrindo espaço para o protagonismo da função da edificação na geração da forma arquitetônica moderna. Forma cuja materialização, no Brasil, estaria vinculada à técnica do esqueleto estrutural de concreto armado.

Neste sentido, a formulação de Costa é importante, pois, no Brasil de 1928, a formação dos arquitetos ainda estava vinculada à Escola de Belas Artes e a arquitetura, enquanto arte, estaria em um campo distanciado da construção. Para este arquiteto, naquele momento, o arranha-céu era um partido de construção que as cidades modernas teriam "fatalmente, mais cedo ou mais tarde, que aceitar em maior ou menor escala", como conclui na entrevista. Independentemente de julgamento de valor, Costa percebeu que o edifício alto seria um dado da realidade urbana no Brasil, com a qual tanto os arquitetos quanto os engenheiros precisariam lidar. De fato, a verticalização do Rio de Janeiro e de São Paulo teve início naquela época, prosseguindo ao longo do século nestas e em outras cidades do país, e a previsão de Costa acabou por se confirmar.

\section{0 SÉCULO XXI E A CULTURA NO CAPITALISMO TARDIO}

A partir do fim da II Guerra Mundial, os edifícios altos construídos em estrutura metálica independente tornaram-se corriqueiros nos grandes centros urbanos dos EUA e em algumas cidades da Europa. As estruturas independentes de concreto armado eram, porém, mais raras. Um exemplar significativo dessa técnica foi construído em 1956 para a Companhia Pirelli, em Milão, com projeto do arquiteto italiano Gio Ponti (1891-1979) e do engenheiro estrutural Pier Luigi Nervi (1891-1979). O edifício de 33 pavimentos e $127 \mathrm{~m}$ de altura era, na época, o único edifício alto de Milão.

A partir da década de 1950, alguns fatores estimularam a construção de edifícios altos em concreto armado. Dentre eles, a melhoria no controle tecnológico do material e a evolução das teorias de análise estrutural. Mas foi, sobretudo, o surgimento dos computadores que permitiu a evolução na velocidade e complexidade dos cálculos, que dão suporte às análises estruturais necessárias à elaboração de projetos desse tipo de edificação. A partir da 
década de 1980, edifícios realmente muito altos passaram a fazer parte da paisagem de algumas cidades do mundo, tendo suas construções possibilitadas pela evolução da técnica, mas também, e principalmente, figurando como testemunhos da cultura surgida na era do capitalismo tardio e da globalização.

As reflexões filosóficas que se deram após o fim da II Guerra trouxeram à luz o conceito de capitalismo tardio, formulado em meio à constatação do avanço da cultura de massa e o surgimento do que o filósofo Theodor Adorno (1903-1969) formulou como "indústria cultural". Atualmente, é possível destacar o crítico de arte Jonathan Crary que, em seu livro 24/7: capitalismo tardio e os fins do sono, chama a atenção para os aspectos do capitalismo no século XXI. Aponta para um capitalismo não mais fundamentado na acumulação de bens, mas no estímulo incessante de necessidades a serem resolvidas por um consumo constante e ininterrupto de serviços. Capitalismo vinculado ao tempo indistinto de operações alimentadas pela disponibilidade permanente de servidores. Surge assim o trabalho sem pausa, que tem por único objetivo gerar o estímulo ao consumo. É no âmbito desta lógica, qual seja a do capitalismo tardio, que se caracteriza o contexto cultural no qual é possível localizar a origem da demanda de construção dos edifícios altos do século XXI.

Os projetos desses edifícios são elaborados a partir de sofisticada análise estrutural, técnicas específicas de logística e pela utilização de equipamentos especiais de construção, bem como de equipes especiali- zadas de mão de obra.Vários desses exemplares foram construídos em países do médio e do extremo oriente, como o edifício sede da Televisão Central da China (CCTV), em Pequim, cujo projeto arquitetônico foi elaborado pelo escritório Office for Metropolitan Architecture (OMA), e o projeto estrutural desenvolvido por Ove Arup and Partners; construção que teve início em 2004 e foi concluída em 2012 (Figura 4).

Outro edifício significativo nesse cenário é o Shangai Tower, construído em Shangai, obra que foi iniciada em 2008 e concluída em 2015, em cuja ficha técnica constam os nomes de empresas como Gensler e Thorton Tomasetti, respectivamente relacionadas à arquitetura e à engenharia. (Figura 5).

O fenômeno de difusão de edifícios altos em vários pontos do mundo deu origem ao Council on Tall Buildings and Urban Habitat (CTBUH). O Conselho estima que, por volta de 2050, as cidades precisarão acomodar um adicional de 2,5 bilhões de pessoas e lança o debate para a solução desse problema. Fornece também uma

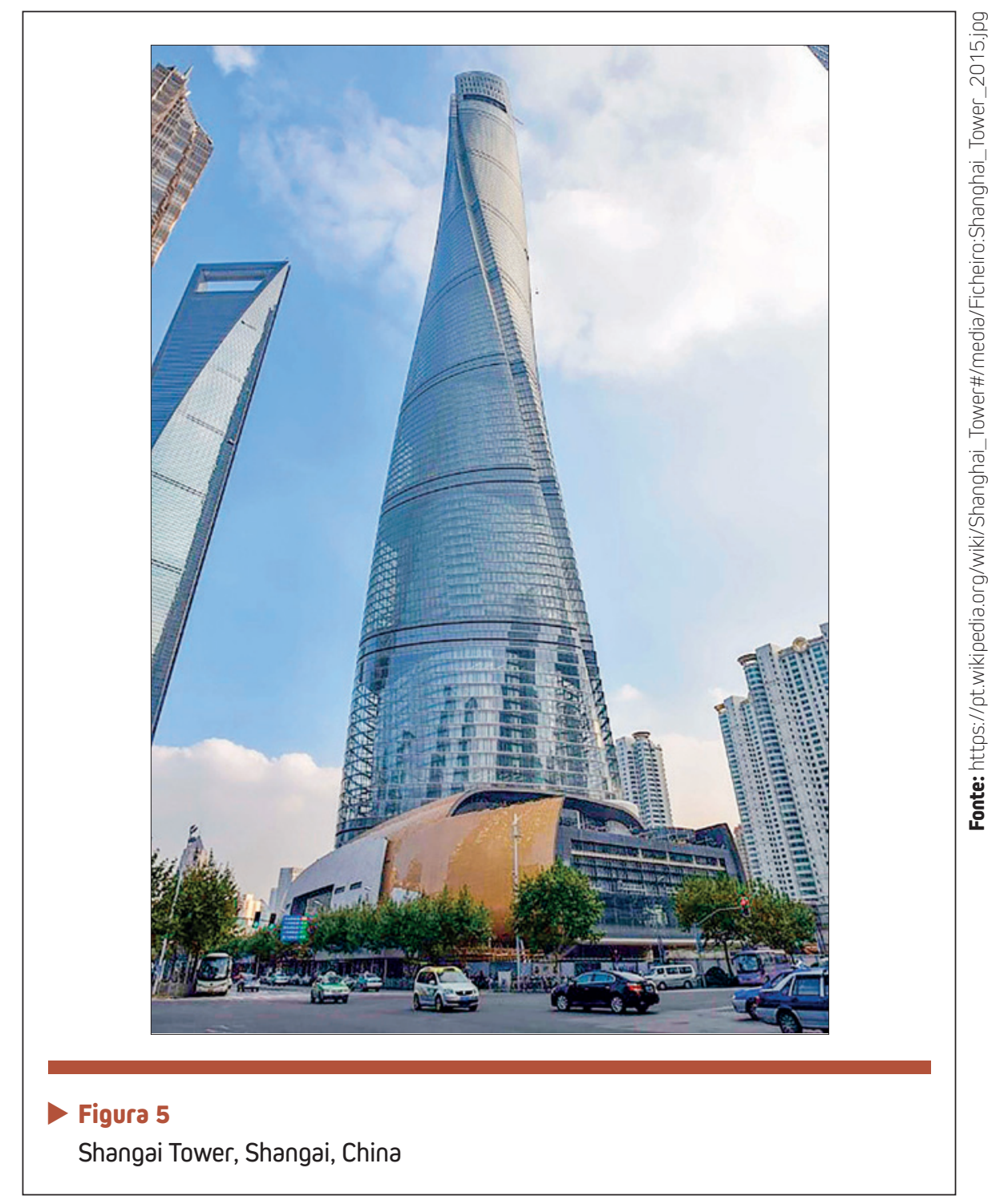




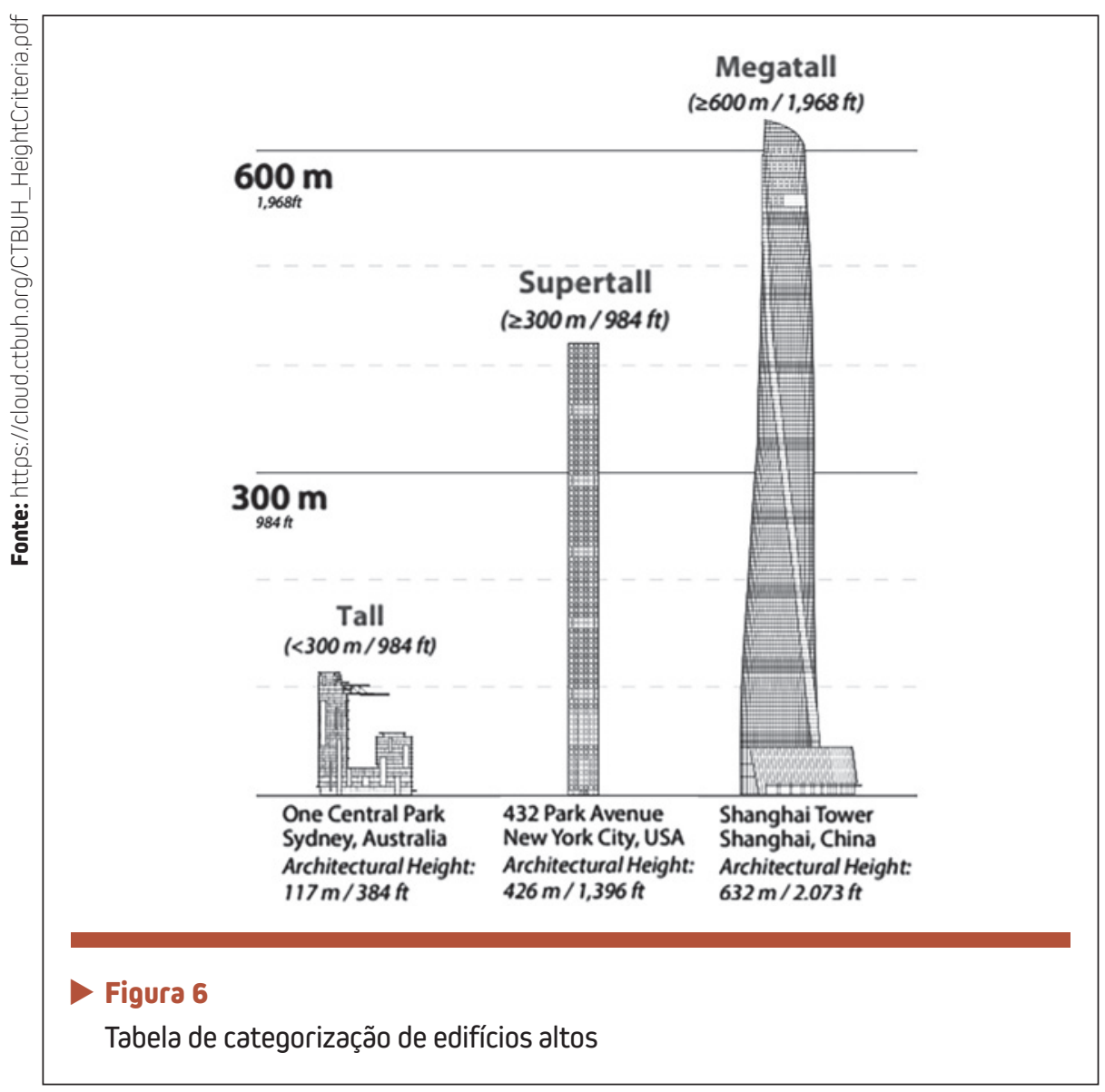

categorização para os edifícios que podem ser: altos, superaltos e mega-altos. A categoria de edifícios altos foi formulada considerando padrões de altura com relação ao contexto, e proporção. Edifícios superaltos são aqueles que atingem 300m de altura ou mais e os edifícios mega-altos são aqueles com alturas a partir de 600m. Segundo o CTBUH existem 115 edifícios super-altos e apenas 3 edifícios mega-altos construídos atualmente (Figura 6).

\section{CONSIDERAÇÕES FINAIS}

Ao se analisar o período que separa os anos de 1880 e 2000, percebe-se, de maneira contundente, a permanência do edifício alto como manifestação de cultura. O capitalismo industrial permitiu à sociedade abastada dos EUA construir os primeiros arranha-céus, materializando ali o poder de um setor da sociedade, um modo de vida e uma manifestação cultural difundida em todo o mundo ocidental. No século XXI, o capitalismo reconfigurou-se em novas bases, sendo reconhecido como capitalismo tardio e caracterizado por sua vigência na chamada era digital, era marcada pelo incentivo ao consumo constante, ininterrupto e sempre crescente.

Os edifícios altos que vêm sendo construídos desde os anos 1980 são edificados a partir de projetos arrojados, que englobam desde a concepção dos espaços às instalações mecânicas, elétricas e de comunicação, a implementação de sistemas digitalizados de vigilância e controle, além de uma arquitetura de interiores específica para atender os anseios da vida na era do capitalismo tardio. São edifícios altíssimos que competem entre si, a partir de projetos elaborados por equipes transnacionais. Edifícios que poderiam estar em qualquer lugar do planeta, independente de aspectos culturais deste ou daquele país e que refletem a cultura do consumo. Representam relações de poder que não se dão mais na arena das nações, e sim das grandes corporações, que, para além da política, participam do controle das esferas da vida do século XXI. É interessante observar que a complexidade dessa cultura planetária continua a ser materializada e simbolizada em edifícios que, como seus predecessores do século XIX, continuam insistindo em arranhar o céu.

\section{REFERÊNCIAS BIBLIOGRÁFICAS}

[1] COHEN, J-L. 0 futuro da arquitetura desde 1889: uma história mundial. São Paulo: Cosac Naify, 2013.

[2] CRARY, J. 24/7: capitalismo tardio e os fins do sono. São Paulo: Ubu, 2016.

[3] CURTIS, W. Arquitetura moderna desde 1900. Porto Alegre: Bookman, 2008.

[4] GIDEON, S. Espaço, Tempo e Arquitetura. São Paulo: Martins Fontes, 2004.

[5] VASCONCELOS, A. 0 concreto no Brasil: recordes, realizações, história. São Paulo: Pini, 1992. 